\title{
The Military Practice of Chiropody LC Gibbard
}

A personal record of wartime activities of chiropodists recruited into the armed forces during the War of 1939 to 1945.

\section{Introduction}

There are few references in the chiropody records concerning the work and duties carried out by chiropodists recruited into the armed forces during the 1939-45 conflict. It relies entirely on the memory of the writer without access to any relevant papers that might exist of a previous constituent body such as the Incorporated Society of Chiropodists.

Around 1938 an agreement was sought by Mr John Hanby, President at that time of the Incorporated Society, between that Society and the War Office concerning possible future use of Society members in a professional capacity in the armed forces in the service of the Crown. The request for this agreement arose from the deteriorating international situation that it seemed would end in conflict. Eventually, such an agreement was drawn up covering members of the Society that were registered medical auxiliaries. It should be noted that all members of the Society were eligible for such registration if they so wished.

A call was then made for volunteers for this work, and their names were passed on to the War Office by the Secretary of the Incorporated Society, Major Lionel W Griffiths. Under the terms of the agreement, the volunteers were to hold a graded army 'trade' designation and a non-commissioned rank. However, in the event, the army trade designation was the lowly one of ' $\mathrm{V}$ ', and the rank applicable to it was the equally lowly one of corporal of the Royal Army Medical Corps. It was felt, however, in recognition by the War Office, that chiropody existed as a specific entity in the army medical services and justified the acceptance even at this low level.

In the event, the War Office was not able to implement the agreement until the autumn of 1940, as there were too many other issues of higher priority. By then many chiropodists had been called up for service in different units, as well as in the navy and the air force.

\section{Preliminary Training}

Those chiropodists, scattered throughout many units of the army, had first to be brought together for integration into the medical services of the army. When they were identified from the records, some 30 of them were posted under War Office orders to the RAMC depot at Boyce Barracks (Crookham Hampshire), and a similar number were brought together at a holding unit at Becket Park, Leeds. Both groups underwent training and instruction in the regimental duties of NCOs for three to four weeks prior to posting to active service units.

\section{The Organisation}

At that time, the country was divided into areas each one of which was, for army medical matters, under the command of an Assistant Director of Medical Services (ADMS) with the rank of colonel. Three or four chiropody corporals were posted to each area and then further dispersed to service units, usually as members of the company providing medical cover for that part of the area. The company headquarters was usually the military hospital for that area and was commanded by a captain, usually a non-medical officer holding a regular or territorial commission. The hospital included on the staff majors of consultant status, general duty medical officers, commissioned or territorial nurses who were state registered nurses and members of Queen Alexandra's Imperial Military Nursing Service, Red Cross and St John nursing auxiliaries and NCOs and men of the unit. A senior medical officer holding the rank of Colonel would command the whole establishment.

The ADMS was responsible for the allocation of medical staff to units in his area. He held a 'pool' of specialists, which he dispersed to service units in his area according to need. Accordingly the chiropody corporals were posted from his pool to the service units.

At this stage in the war (1940) large numbers of men were being recruited and trained, so chiropodists found themselves posted to training units that could be either infantry, artillery or parachute. A little later in the war, as more women were recruited for the ATS, their training units had to be staffed as well, either by ATS corporal chiropodists recruited into that service or by male chiropody corporals of the RAMC.

Each training wing had a medical section usually situated in what was known as the 'Camp Reception Station' (CRS). This comprised a medical inspection room, treatment room, dispensary, record office and medical officer's surgery. It was usually freestanding and detached from the rest of the barracks. It was staffed by a medical officer, a senior NCO clerk, a sergeant dispenser, a junior NCO in charge of the medical orderlies and general duties orderlies. To this staff was attached a chiropody corporal.

Prior to being posted to a CRS it was usual for newcomers to the unit to be retained at headquarters for some time in order to get to know them and to assess their capabilities. The aim of army discipline is to consolidate all its parts into a solid cohesive body capable of direct and, if required, immediate action. This means that individual thought and action is frowned upon and precludes action until an order is given.

One of the privileges accorded to chiropodists in civilian practice has always been to permit freedom of thought and action, especially in a clinical sense. It became difficult therefore for chiropodists to integrate themselves into the 'straight jacket' of army discipline. However, within this overall disciplinary 'cover' a fair amount of latitude was possible if exercised with care.

To begin with, the army did not know what chiropodists were nor what they did, let alone how to use them in their 'trade'. However, they found a use for them as additional corporals available for regimental duties and as additional staff for the CRS.

There were sick parades to attend and health parades for troops posted away from the training units to active service units. These latter were known as 'Free from infection' inspections (FFIs). However, the core duties were focused on the treatment of patients retained in the CRS. The medical officer (MO) was responsible for all health matters in barracks, and when carrying out inspections was accompanied by an NCO to make notes and to ensure the MO's instructions were passed to the barrack officers to be carried out. This duty was usually given to a junior NCO; hence the chiropody corporal was often used for such duties. Foot inspections of the new recruits provided an opportunity for the chiropody corporal to come into his own and establish a good rapport with the medical officer, which was essential for the establishment of a chiropody clinic in the barracks. 


\section{Case of chiropody instruments - 1938 pattern $(19.5 \times 14.0$} x $3.0 \mathrm{~cm}$ ). Copyright JC Dagnall September 1998 .

\section{Accommodation, supplies and equipment}

As the army had no idea of the particular requirements of chiropodists, and no special equipment or supplies were available. To begin with, chiropodists had to make use of any medical furniture or equipment found in the CRS or obtainable from the barrack warden's stores. Adaptation and improvisation was the order of the day. The only instruments available were in a foot orderlies' box, which contained a pair of heavy nail nippers, a pair of scissors, a heavy scalpel and a coarse file that would have done credit to a heavy engineering workshop and that had a pointed 'pick' on the end of the handle. Altogether they constituted a very clumsy 'set of tools'.

It was possible to order felts and plasters from the medical stores at the hospital, but they were in short supply and in any event were claimed by the orthopaedic surgeons. There was also difficulty in getting supplies released from the hospital.

There were difficulties, too, in finding accommodation in the CRS, which was constantly in demand for sick parades and treatments that the medical officer had ordered to be caried out, and also for inoculations and a host of minor and sometimes major casualties brought in by ambulances from neighbouring units. There was also heavy pressure on accommodation, with new recruits arriving just as soon as trained squads were sent out to active service units. The training staff, usually time-serving NCOs under the control of the Regimental Sergeant Major (RSM), were permanently garrisoned in the barracks and lay first claim on accommodation. Eventually it was possible to find a room or part of a room to use as a chiropody treatment area, but even this might require the intervention of the MO who would interview the RSM and put the chiropodist's case to him, often with a certain amount of vigour.

\section{War Service Duties as a Corporal Chiropodist}

On leaving Boyce Barracks three of us were posted to Number 22 Company RAMC at Stoke Dameral Military Hospital Devonport, and eventually onward to training units at
Honiton, Exeter and Camborne. The Honiton camp was an ATS training unit and Camborne and Exeter were infantry depots.

At the HQ Hospital we had been employed on junior NCO duties, as there were no facilities for chiropody. I remember being in charge of the regimental police as my first job and then being put in charge of the medical inspection room. Here I had to run the sick parades, give treatments and admit patients to the hospital. I also had to take charge of the mortuary.

I don't think anyone realised how little training we had received as very early on I was told to give a patient gas and then to open up an intrathecal whitlow on the soldier's thumb while the MO sat at his desk reading. Subsequently I was arraigned before the Colonel for failing to cover a corpse with a union flag when conveying it to the mortuary, and all this in the midst of a heavy air raid!

At Exeter things were very different. The posting was to the depot of the Devon Regiment and medical services here were run at a CRS by a Colonel on retired pay, who, although employed as a civilian, continued to wear a full Colonel's uniform with red gorget patches and all the badges of rank and decorations. He was, in fact, a retired surgical specialist. In barracks he was accorded full military respects and woe betide any young recruit who failed to give him a full salute when passing him outdoors, provided they both had their caps on, of course!

We were a small detachment, staff sergeant, two sergeants one a dispenser the other a clerk, two nursing orderlies and myself as a corporal - all RAMC. In addition were four Devon regiment orderlies whose job was to keep the place clean, collect meals from the cookhouse and do what ever else was needed. We provided 24-hour cover, so the retired Colonel, who lived out of barracks, was on continuous standby and could be contacted by telephone any hour of the day or night.

Apart from the officer commanding the Devon regiment, he was the only other high-ranking officer in barracks, which gave him much prestige. This was very advantageous to us for the respect given to rank in the army is so great that any requests or orders to the Devon regiment made over his signature were immediately acceded to. By these means I was able to obtain a couple of rooms in an old married quarters block in which to establish a chiropody centre.

The rooms were quite bare with no furniture or equipment except for a box of army chiropody instruments (1931 pattern) described earlier and that in the past were issued for use by battalion foot orderlies who had undergone a 24-day course of lectures and demonstrations by an officer of the RAMC. There was also an Army Manual of Chiropody, which was distinctly primitive and contained nothing of any use to a properly trained chiropodist. I then acquired a barrack room table and some chairs from the barrack warden as well as some supplies of simple drugs and dressings from the CRS and 'set up shop'.

With recruit training in full swing it became necessary to organise the chiropody centre properly. I persuaded the sergeant dispenser to send in requests for felts and plasters and various drugs used as well as instrument dishes and glass containers. Eventually most of these supplies arrived. I drew on the CRS for operating gowns and towels and the use of their steriliser, which was rather primitive being a stainless steel dish mounted over a spirit burner.

My real need, in order to give treatment more easily, was for an adjustable footrest and a platform. Accordingly, I sought out the regimental pioneers one of whom I found was a carpenter. He was quite willing to make what I wanted provided I supplied him with a proper set of drawings and a signed order, 
which I did. After a few weeks he came back with a well-made adjustable footrest and a platform, which made work so much easier despite the crude instruments I had to use. For my own comfort and contentment I sent for a selection of my own instruments, and when they arrived I was able to work to proper standards.

The training of infantrymen is based on marching, the heavy marching schedule in new boots takes its toll on feet. The commonest injuries sustained were blisters, which required simple protective dressings. After a route march it was quite common for 30 or 40 tired men to crowd into the CRS treatment room for attention, mostly with foot lesions. The orderlies there were quite used to doing dressings for simple lesions. I dealt with anything more complicated or difficult in the chiropody centre. As the new intakes settled down and discovered what the chiropody centre had to offer so the numbers of patients increased. Corns, painful nails and mild footstrain were the most common conditions seen, although there were occasional cases of acute foot strain.

These latter were referred to the MO with a written request for treatment, which usually was to excuse the patient from wearing boots. This meant they wore plimsolls around barracks and avoided route marches, and they were found some sort of job around barracks to keep them occupied. I found this unsatisfactory as the use of soft plimsolls exacerbated the footstrain and delayed recovery. It also interrupted the recruits' training schedule as the training NCOs had only 10 weeks to toughen up recruits and get them through a 20-mile route march with a full pack, and they did not like recruits being taken out of their squads and any who failed the course had to do another 10 weeks. To avoid this, I asked the MO if these patients could be kept in boots and excused marching for three days, during which time they would have contrast footbaths. This worked out quite well except for a few cases that went into spasm. These the MO admitted to the ward for bed rest and continued contrast footbaths, and they were usually able to return to full duty in a week with the assistance of some padding and strapping.

Exeter was a fully garrisoned city, and there were three other units in and around it. There was a large artillery barracks, just as busy training recruits as the Devon depot, a Pay Corps unit and an ATS unit, where the girls working as pay and record clerks had their own offices.

The situation at the artillery barracks was, from the chiropody point of view, identical to that at the Devon depot. However they had no CRS to rely on and if necessary had to use the CRS in the Devon barracks, while the ATS had their own CRS at their quarters. When it became known that there was a chiropodist at the Devon depot there was a demand for the same at the other barracks. As a result I found myself seconded to other units for two days a week, where patients were seen in the medical inspection rooms. I used to travel between them using my bicycle (it was not until much later that I discovered that I was entitled to claim one farthing per mile for the use of my own bicycle on official army work!).

The girls' main complaint was their dislike of wearing ATS issue shoes, because of the low heels, hard, inflexible uppers and unattractive styling. In the recruit stage they suffered badly from blisters, nail trouble and muscle fatigue, particularly of the calf muscles. However, eventually they became used to the footwear and tolerated the shoes quite well. Their other trouble was chilblains; all sorts of remedies were tried, sent from home by anxious mothers, but painting with iodine solution or friars balsam was all that was available. The two conditions that, I was surprised to find, were comparatively rare were verrucae and athlete's foot. I offered to treat both conditions, but the medical opinion was that they should be sent to the dermatologist on account of their possible spread.

Having to travel to various units scattered all over the city gave me a degree of freedom to arrange my own work to the best advantage. This was a privilege not normally accorded to a junior NCO and one that I guarded jealously. Nevertheless I had to take my place in the team, giving 24-hour health cover to the garrison, particularly during times of stress or emergency when the provision of chiropody treatment was abandoned, and clinical hours and visits were stopped often without notice. One such occurrence was the series of 'Baedecar' raids in May 1942.

The city was 'blitzed' and the centre burnt out. Earlier it had become known that I was an officer of the St John Ambulance brigade and had undergone training in air raid precautions, casualty service organisation and anti-gas decontamination procedures to Home Office standards. The army was not slow to take advantage of this and I was told to instruct the Devon regiment bandsmen as first aid men and stretcher-bearers, which is the band's usual duty on active service. This was followed by training the CRS staff, senior NCOs included, in anti-gas and decontamination work. In the event of gas being used I was to open the decontamination unit in the barracks. Fortunately this never happened but we were ready all the same.

\section{Military Hospital Duties}

The autumn of 1943 saw a change in the nature of military training, with fewer and fewer recruits being called up, as the army, at least, had nearly its full complement of men. The real need was to keep all the ranks occupied and in good health until the strategic planning for the invasion of Europe and the necessary supplies were ready.

Accordingly, I was withdrawn from the CRS, the chiropody centre was closed down and I was posted back to the main hospital. This had earlier been evacuated from Plymouth on account of constant air raids and re-sited in a large country hotel on the edge of Dartmoor. I had some previous experience of working at this site, as I had been withdrawn from the CRS on several occasions to run training courses for battalion foot orderlies. There were no facilities for chiropody at the hospital so I was used as a spare NCO for a variety of other duties. At times I was put in charge of hygiene, sanitation and water supply or any other odd jobs, which sometimes included escort duty - taking military prisoners after sentence at court martial to the military hospital at Chatham. Ultimately I was again put in charge of the M1 room.

After morning sick parade there was little to do here apart from the admission of patients sent by MOs of holding units and searchlight batteries in the neighbourhood. I gradually made it possible to carry out some chiropody here until one day one of the surgeons walked in and found me sharpening my own instruments. He was immediately interested as there had been some difficulty in getting instruments sharpened. The outcome of this was that I spent much of my time cleaning, sterilising and sharpening surgical instruments and ensuring that the operating room was kept ready for use at short notice. When operations were carried out I had to be in attendance as I was the only person who knew where everything was kept!

I had been occupied with this work for about six months when, reporting for duty one morning, I saw the Number five mobile chiropody unit standing outside the main entrance to the hospital. I then did two almost unheard of things: I went to the orderly room (company office) and, through the RSM, made a request to the company captain to be posted to and put 
in charge of this mobile unit, and then I rang the chief clerk at the ADMS and repeated my request.

There is nothing the army likes better than submitting and receiving reports, which must always be in triplicate. When running the chiropody centre at Exeter I had, every month, assiduously submitted a report on the numbers of patients seen and the conditions treated. One copy was addressed to my local MO, in this case the retired Colonel, another to the Colonel in charge of the hospital and the third to the ADMS himself. As a result I was well known, on paper that is, to the two active service Colonels concerned, and by agreement between them I secured a posting to the mobile unit.

\section{The Mobile Units}

As the war progressed it became apparent that the heavy concentrations of troops in the large camps and training centres were being reduced and, as a result, chiropodists were being used as spare corporals on general duties rather than doing their proper work. At the same time the troops were being kept fit, healthy and occupied by a series of long route marches, and it was proving impossible to give them the chiropody treatments they needed. The military hospitals had found it advantageous to add the chiropodists to their establishments to employ their medical skills and knowledge with out the necessity of further training.

As comments on the change of service, use and conditions filtered back to the Council of the Incorporated Society of Chiropodists, the Scottish members of Council put forward the idea of raising funds to equip mobile units and present them to the army medical service. For some time mobile chiropody units, run by the British Red Cross Society in Scotland, had been shown to be most useful in taking the service to scattered villages. The Council discussed and approved this idea, and an appeal was made to members for funds to make this possible. Eventually, five units were purchased and presented to the army medical service.

The Number five unit was presented to the ADMS at Taunton, who sent it to Number 22 Military Hospital at Moretonhampstead. This was most appropriate, as the funds to provide it had been raised in the West Country due to the efforts of a Miss Joyce Meyer in Bristol.

\section{Description of the Units}

The mobile units consisted of a light-weight van body mounted on a Ford Prefect chassis. Considerable thought and ingenuity went into the design and construction of these units as well as their fitting out. To obtain a vehicle of any kind was difficult at that time, as everything was in short supply. Very little civilian motoring was possible because of the severe petrol rationing and many motorists had given up private motoring and laid up their cars, and it was these cars that provided our source.

The back half of the body had to be removed and a van body constructed to fit the chassis. This was made of a wooden frame covered with hardboard panels large enough to accommodate a Hinder's tubular steel patient's chair complete with leg rests and other necessary equipment. The front seats and windscreen remained but a new roof was needed.

In addition to the patient's chair, room had to be provided for the operator's chair, an adjustable lamp on a jointed stand and a cupboard fitted out to take storage jars, instrument dishes and a bottle stand. All these items had to be made safe and secure either by being strapped down or fitted into slots and held firmly by a turn button yet easily removable for use.

No space was left to accommodate any military equipment that might have to be caried, i.e. two gas masks, the driver's rifle, personal kit, rations, blankets and spare clothing for two persons. The addition of these items caused the unit to be grossly overloaded and, as might be expected, this unit eventually broke down and was off the road for several months being repaired and partly rebuilt by civil contractors and the Royal Army Service Corps (RASC). During this time a replacement vehicle was borrowed from the RASC. This was a sheet-covered one-ton lorry that, although it took the load quite well, did not accommodate the equipment safely or securely, which resulted in some damage to it and the loss of items of personal and military equipment. It was also very exposed to the weather as there was no proper windscreen, only two small deflectors in the cab.

This vehicle was in use in the very cold winter of 1944-45, during which time it was necessary to warm up the crew on arrival at each site before unloading could be carried out and work commenced. At this time many of the troops to be visited were scattered widely across the countryside in comparatively small numbers. They were engaged in manning searchlights, which acted as lamplights guiding the returning bombers back to their bases by flashing the lights across the sky in the direction of their home bases. Many ATS girls were working in these sites carrying out full active service duties, and were often in need of chiropody treatment. We were very relieved to get the Ford Prefect back after six months, as our work required a sturdy vehicle.

Slowly but surely the barracks in the garrison towns and cities of the south-west began to fill up once more as preparations for the continental invasion began. It became necessary to contact the ADMS once more, this time to obtain another chiropodist to take over the garrison work and free the mobile unit for visiting the outlying units. This state of affairs continued until the invasion of Europe took place, when it became apparent that the mobile unit would prove very useful overseas. Accordingly I suggested it be sent for that purpose. However, the vehicle was judged insufficiently robust by the RASC. I left the mobile unit for demobilisation in January 1946 when it was taken over by another chiropodist.

Before finally leaving service matters, mention should be made of the educational possibilities of the army, which are very good provided one's duties permit participation in them. Fortunately, during the year I was working in Number 22 Home Based Hospital and the 18 months I had in charge of the mobile unit, my duties were sufficiently flexible to permit my taking advantage of them.

This was encouraged both by the Army Education Corps Captain attached to the Exeter garrison and the officer in charge of the Army Bureau of Current Affairs at Ilfracombe. The former was able to provide the books I needed to complete the reading course in psychology. I had started back in 1937 under the auspices of the Oxford University Extension lectures scheme.

The Army Bureau of Current Affairs was able to obtain for me the prospectus of emergency training for prospective teachers returning to civil life after demobilisation. I applied for and was refused enrolment for that course as I already had a qualification in chiropody. It was just as well that I was refused as I had obtained my chiropody teachers certificate in 1945, which was of more use in obtaining the teaching post at the Manchester Foot Hospital School of Chiropody advertised in 'The Chiropodist' in December 1945. I was appointed to this post as from February 1st 1946 and held it until transferring to the Northern College of Chiropody at Salford in 1960. 


\section{Conclusion}

I have tried to give general record of the practice of chiropody in a military environment as I found it as well as a particular report on the way it affected my own thoughts and actions at the time.

It must be remembered that the first duty of a soldier is to be efficient and well disciplined. The possession of a trade or specialist ability is an additional contribution by the soldier to his unit. Chiropodists, therefore, in this situation, will be treating members of a specially picked group of patients in a closed environment who are normally fit, healthy, very active and mostly young - almost the opposite of patients treated in civilian practice. Nevertheless, the basic treatments required are very similar and need little modification for military use. Additionally, chiropodists are likely to be called upon to treat a variety of injuries ranging from training accidents (particularly in parachute units) to battle casualties, if attached to field ambulance units or nursing duties if working in a hospital. All of these require special training and adaptability.

The forces are a world of their own with food, clothing, accommodation, sport, entertainment, education and healthcare all provided. The soldier's main concern is for his own work and well being, away from family, familiar scenes and freedom, so it takes hardiness of spirit and adaptability of character to cope both with service life and professional practice.

The above paper was brought to our attention by Col TP Finnegan late RAMC and is reproduced by kind permission of 'Podiatry Now' where it was first published in February 1999. 